\title{
On the Importance of Ions and Ion-Molecule Reactions to Plasma-Surface Interface Reactions
}

\author{
Keri L. Williams, Ina T. Martin, and Ellen R. Fisher \\ Department of Chemistry, Colorado State University, Fort Collins, Colorado, USA
}

Ions are known to be key players in many plasma processes, including anisotropic etching, film deposition and surface modification. The relationship between plasma ions, film properties, and surface interactions of other plasma species is not, however, well known. Using our Imaging of Radicals Interacting with Surfaces (IRIS) technique, along with plasma ion mass spectrometry (PI-MS), and surface analysis data, we have measured the effects of ion bombardment on the surface interactions of $\mathrm{SiF}_{2}$ in $\mathrm{SiF}_{4}$ plasmas and of $\mathrm{CF}_{2}$ in $\mathrm{C}_{3} \mathrm{~F}_{8}$ and $\mathrm{C}_{4} \mathrm{~F}_{8}$ plasmas. $\mathrm{SiF}_{2}$ is a known product of $\mathrm{F}$-atom etching of $\mathrm{Si}$, and $\mathrm{CF}_{2}$ has also been cited as a product of fluorocarbon etching of $\mathrm{Si}$. With both molecules, we measure surface generation when the surface is bombarded by all the plasma species. Removal of ions from the plasma molecular beam results in a net decrease in surface generation for both molecules at all powers. Results in both systems are compared with the gas-phase ion-molecule reaction data of Armentrout and coworkers. Preliminary guided-ion beam mass spectrometry results taken in the Armentrout laboratories for the $\mathrm{Ar}^{+}+\mathrm{C}_{3} \mathrm{~F}_{8}$ reaction system are also presented. (J Am Soc Mass Spectrom 2002, 13, 518-529) (C) 2002 American Society for Mass Spectrometry

$\mathrm{P}$ lasmas are widely used in the microelectronics industry to etch and deposit a variety of materials including amorphous hydrogenate silicon (a-Si: $\mathrm{H})$, silicon dioxide, silicon nitride and silicon carbide [1]. Fluorine-containing plasmas are especially useful as $\mathrm{F}$ atoms are known to etch Si-based materials [2], fluorinated silicon alloys can be deposited by addition of appropriate diluents [3], and fluorocarbon plasmas (FCPs) both deposit polymeric fluorocarbon layers and can be used to clean processing tools [4]. Plasmas are also used in a variety of other industrial regimes for the production and modification of surfaces, with applications ranging from improved adhesion between metals and polymers to modification of porous polymeric materials.

Despite these widespread uses and the vast body of literature on plasma chemistry, many of the details for the mechanisms by which plasma etching and polymerization occur remain poorly understood. During etching, energetic species including ions and radicals work to remove the underlying substrate, preferably in a selective fashion. In this way, a variety of features can be produced. It is generally believed that ions enhance the etching process in a directional or isotropic manner [5]. During plasma deposition, ions, radicals, and pho-

Published online April 2, 2002

Address reprint requests to Ellen R. Fisher, Department of Chemistry, Colorado State University, Fort Collins, Colorado 80523-1872, USA. E-mail: erfisher@lamar.colostate.edu tons work synergistically in the polymerization process, to form a thin film of material. Although early workers in the field of plasma polymerization identified ions as important film precursors [6], radical species are most often cited as polymerization building blocks. Recently, Hanley and coworker have shown that ion beams of hyperthermal ions can produce thin films and can be used to modify material interfaces $[7,8,9]$. The size and structure of the ions used (i.e., $\mathrm{CF}_{3}^{+}$vs. $\mathrm{C}_{3} \mathrm{~F}_{5}^{+}$) can strongly affect film composition, structure, and surface reactivity of the ion. These experiments, however, do not examine the effects of ions on film composition in the presence of the full range of plasma species.

In addition to ion-surface interactions, the role of gas-phase ion-molecule reactions is still unclear in both plasma etching and plasma polymerization processes. In many plasma polymerization systems, ion-molecule reactions clearly lead to formation of oligomeric species $[10,11]$. Ion-molecule reactions can often lead to different product branching ratios than those produced via electron impact reactions. Moreover, some researchers believe ion-molecule reactions that lead to large, polyatomic gas-phase ions are key steps in the overall polymerization process in a variety of FCPs (i.e., $\mathrm{C}_{2} \mathrm{~F}_{6}$ and $\mathrm{C}_{4} \mathrm{~F}_{8}$ ) [12]. Armentrout and coworkers have used ion-molecule reactions to determine much of the relevant thermochemistry and reaction rate data for species of interest in plasma deposition and etching [13]. These 
data are useful for both modeling efforts and for determining gas-phase reaction mechanisms.

It is also critical to have an understanding of how gas-phase plasma ions influence the surface interactions of other plasma species. For example, ion bombardment assists both film deposition and anisotropic etching through surface bond breakage (thereby increasing product formation and desorption) and by enhancement of surface reaction kinetics [5]. Recent experimental [14] and theoretical $[15,16]$ work has shown that energetic ion bombardment can also yield gas-phase species by mechanisms of neutralization followed by dissociation, and by sputtering of already deposited films.

Characterization of gas-phase plasma species and gas-surface interactions during plasma processing can be achieved with our Imaging of Radicals Interacting with Surfaces (IRIS) technique [17]. This method combines molecular beam and plasma technologies with spatially-resolved laser-induced fluorescence (LIF) to measure radical-surface interactions. Furthermore, this method enables the exploration of the dependence of the surface reactivity (or surface loss coefficient) on plasma processing conditions, substrate material, substrate temperature $\left(T_{\mathrm{S}}\right)$, and ion bombardment because the use of a molecular beam facilitates independent variations of the plasma and surface conditions. The effects of ion bombardment can also be explored, as described in detail below. In addition, the IRIS apparatus is equipped with an inline mass spectrometer for identification of both neutral and charged plasma species in our plasma molecular beam.

We have also used the IRIS apparatus to examine the energetics of plasma species as well as molecules scattering off of processed substrates. The IRIS experiment allows the study of both the kinetic translational temperature $\left(\Theta_{T}\right)$ and the rotational temperature $\left(\Theta_{R}\right)$ of plasma species with relatively high accuracy [18]. Comparison of $\Theta_{\mathrm{T}}$ for species in the plasma and those scattering off of a substrate provide insight into energy accommodation by surfaces and can also be used to elucidate radical-surface interaction mechanisms [19, 20].

In the present work, we examine the effects of ion bombardment on the surface interactions of two species. Focus will be on $\mathrm{SiF}_{2}$ in $\mathrm{SiF}_{4}$ plasmas and the isoelectronic difluorocarbene, $\mathrm{CF}_{2}$, in $\mathrm{C}_{3} \mathrm{~F}_{8}$ and $\mathrm{C}_{4} \mathrm{~F}_{8}$ plasmas. In all cases, $\mathrm{Si}$ substrates were used as both $\mathrm{SiF}_{2}$ and $\mathrm{CF}_{2}$ are considered products of $\mathrm{Si}$ etching reactions. In general, however, the conditions employed with the $\mathrm{C}_{3} \mathrm{~F}_{8}$ and $\mathrm{C}_{4} \mathrm{~F}_{8}$ plasmas lead to net deposition of a fluorocarbon polymer. Two methods were used to ascertain the influence of ion bombardment on the molecule-surface interactions: a grounded mesh screen in the path of the molecular beam which eliminates the majority of charged species and positive and negative substrate biasing, which either accelerates or deflects impinging ions from the substrate. In addition, comparison is made with available ion-molecule reaction data on related systems from the work of Armentrout and coworkers. In the $\mathrm{C}_{3} \mathrm{~F}_{8}$ system, we report preliminary results for the $\mathrm{Ar}^{+}+\mathrm{C}_{3} \mathrm{~F}_{8}$ reaction system for direct comparison to the plasma ion mass spectrometry (PI-MS) data as well as the $\mathrm{CF}_{2}$ surface interaction data for this system. Where instructive, surface analysis data are shown to complement the gas-phase and gas-surface interface data.

\section{Experimental Details}

\section{IRIS Apparatus}

The IRIS apparatus has been described in detail previously [17]. In a typical IRIS experiment, an inductivelycoupled plasma $(13.56 \mathrm{MHz})$ is created in a glass reactor, and the plasma is expanded into a doubledifferentially pumped high-vacuum chamber. This generates a collimated, near-effusive molecular beam consisting of virtually all species present in the plasma. A tunable laser beam intersects the molecular beam downstream from the plasma source and excites a specific species of interest. Using spatially- and temporally-resolved LIF allows the study of either the interaction of the radicals with surfaces or the velocity of the radicals in the molecular beam. For reactivity measurements, the LIF intensity of a species in a freely expanding molecular beam is compared with the LIF intensity of the same species with a substrate in the path of the molecular beam. The difference in LIF intensity is directly proportional to the amount of radicals desorbing from the substrate surface (both scattered species and those created at the substrate's surface).

For reactivity measurements, the laser intersects the molecular beam at a $45^{\circ}$ angle, and is parallel to the substrate. The laser-surface distance is maintained within the range of $2-5 \mathrm{~mm}$. Total fluorescence is detected by an intensified charge-coupled-device (ICCD, Princeton Instruments) located perpendicular to both the molecular beam and the laser beam, directly above the interaction region. The ICCD is electronically gated with respect to the trigger of the laser pulse (gate delay) and signal is collected during the gate width. Fluorescence is collected by a set of two lenses, with focal lengths of 300 and $75 \mathrm{~mm}$, imaging a $2030 \mathrm{~mm}^{2}$ area onto the $586 \times 384$ pixel array of the ICCD.

The molecular beam sources were plasmas created with: $100 \% \mathrm{SiF}_{4}$ (Matheson, Newark, CA, USA, $99.9 \%$ ); $100 \% \mathrm{C}_{3} \mathrm{~F}_{8}$ (Air Products, Denver, CO, USA, 99\%); and $100 \% \mathrm{C}_{4} \mathrm{~F}_{8}$ (Matheson, 99.99\%). In each system, the source pressure was maintained at 30-100 mTorr and the applied rf power, $P$, ranged from $20-170 \mathrm{~W}$. An excimer-pumped $(\mathrm{XeCl}, 100 \mathrm{~mJ}, 100 \mathrm{~Hz})$ dye laser system and the appropriate dye for each molecule was used to induce fluorescence. The spectral regions of interest were $219-224 \mathrm{~nm}$ for $\mathrm{SiF}_{2}$; and $229-240 \mathrm{~nm}$ for $\mathrm{CF}_{2}$. In all experiments, the substrates used were $2 \times 3$ $\mathrm{cm}$ pieces of Si (100) wafers that were cleaned by sonication prior to use. For both molecules, measurements of the fluorescence signal as a function of the laser energy yielded typical optical saturation behavior for the transitions investigated. All reactivity and veloc- 
ity experiments were performed at energies in the optical saturation regime such that the measurements are not affected by small fluctuations in laser power. LIF signals were collected for multiple accumulations with exposure durations of $10 \mathrm{~s}$ to $3 \mathrm{~min}$ and background images were subtracted from the data images. 1-D cross sections of the images were made by averaging $\sim 20$ columns of pixels $(7.74 \mathrm{~mm})$ and plotting signal intensity as a function of distance along the laser beam path.

\section{Data Analysis}

To extract the surface reactivity of the radicals, the numerical simulations described previously are used to model the cross sectional data $[17,21]$. Briefly, the spatial distribution of the radical number density along the laser beam is calculated for radicals in the molecular beam and for those scattered at the surface based on the known geometry of the experiment. In the simulations, all incident radicals scatter from the surface (i.e., zero surface reaction probability) with an assumed cosine distribution about the surface normal. The resulting simulated curve for the scattered radicals is compared to the corresponding experimental data and the radical's surface reaction probability is derived from the scaling factor or scattering coefficient, $S$, necessary to match the experimental data. A value of $S<1$ means that radicals are lost at the surface with a surface reaction probability, $R=1-S$, whereas $S>1$ indicates surface production of the radical species. $R$ can be considered an effective surface reactivity or surface loss probability. As extensive surface generation of radicals occurs in the systems described here (i.e., $S>1$ ), the present results are reported as scatter coefficients.

\section{Plasma Mass Spectrometry}

In addition to IRIS data, plasma ion mass spectrometry (PI-MS) data were acquired for the $\mathrm{SiF}_{4}, \mathrm{C}_{3} \mathrm{~F}_{8}$, and $\mathrm{C}_{4} \mathrm{~F}_{8}$ plasma molecular beams to identify ionic beam species and to determine the extent of removal of ions in the grounded mesh experiments. For these data, the rear flange of the IRIS chamber was replaced with a flange that has a quadrupole-based mass analyzer mounted on it. This configuration allows the direct sampling of the molecular beam. Data were acquired with the ionizer set to $30 \mathrm{eV}$, providing spectra of all the species in the molecular beam (including species resulting from fragmentation in the ionizer). More importantly, data were also acquired with the mass spectrometer ionizer turned off. This allows for identification of nascent ions in the plasma molecular beam. With both configurations, data were acquired as a function of the applied plasma power. Here, we focus primarily on the nascent ion spectra for information on relevant ionic species.

\section{Surface Analysis}

X-ray photoelectron spectroscopy (XPS) analyses of fluorocarbon films deposited in independent plasma reactors [22] were performed on a PE5800 spectrometer equipped with a $2 \mathrm{~mm}$ monochromatic $\mathrm{Al} \mathrm{K} \alpha \mathrm{X}$-ray source $(h \hat{\imath}=1486.6 \mathrm{eV})$, hemispherical analyzer, and resistive strip multichannel detector. A low energy $(\sim 1-5 \mathrm{eV})$ electron gun was used for charge neutralization. For all samples, multiple spots were analyzed. Survey spectra were taken with a pass energy of 93.90 $\mathrm{eV}$ and the high-resolution $\mathrm{C}_{1 \mathrm{~s}}$ spectra were acquired with an analyzer pass energy of $23.50 \mathrm{eV}$. All data were collected at a $45^{\circ}$ takeoff angle (the angle between the surface normal and the axis of the analyzer lens), and were fit using Gaussian functions.

\section{Guided Ion Beam Mass Spectrometry}

Ion-molecule reaction cross-sections for the $\mathrm{Ar}^{+}+\mathrm{C}_{3} \mathrm{~F}_{8}$ system were acquired using the guided ion beam mass spectrometer (GIBMS) in the Armentrout laboratory at the University of Utah [23]. Ions were produced in a flow tube ion source described previously, focused into a beam, mass analyzed, and decelerated to a desired kinetic energy. The ion beam is injected into an rf octopole beam guide, which acts as an ion trap [24], and passes through a reaction cell containing a neutral reactant gas at sufficiently low pressure to ensure single-collision conditions. Product and unreacted ions drift out of the gas cell to the end of the octopole where they are focused into a quadrupole mass filter for mass separation and detected using a secondary electron scintillation detector and standard ion pulse counting techniques.

Laboratory (lab) ion energies are converted to energies in the center-of-mass $(\mathrm{CM})$ frame, $\mathrm{E}_{\mathrm{CM}}$, the energy available for chemical reactions using $\mathrm{E}_{\mathrm{CM}}=\mathrm{E}_{\mathrm{lab}} m /(m+M)$, where $m$ and $M$ are the masses of the neutral and ionic reactants, respectively. At each $\mathrm{E}_{\mathrm{CM}}$, the intensities of the transmitted reactant and product ions are converted to absolute reaction cross sections, $\sigma$, for each product channel as described previously [23]. These cross sections have absolute uncertainties of $\pm 20 \%$ up to $\pm 50 \%$ for some charge transfer reactions. Relative cross section values are accurate to about $\pm 5 \%$.

\section{Results and Discussion}

\section{Fluorosilane Plasmas}

Fluorosilane-based plasmas have been used to both etch and deposit Si-based materials. In $100 \% \mathrm{SiF}_{4}$ plasmas, selective etching of $\mathrm{Si}$ over $\mathrm{SiO}_{2}$ and $\mathrm{Si}_{3} \mathrm{~N}_{4}$ has been achieved [25]. Etching in these systems has been attributed to processes such as F-atom reactions with $\mathrm{Si}$ atoms, radical-surface reactions, and ion bombardment [26]. Adding a suitable diluent (e.g., $\mathrm{O}_{2}$ or $\mathrm{H}_{2}$ ), results in deposition of fluorinated silicon alloys [3]. The balance between etching and deposition in $\mathrm{SiF}_{4}$-based systems 

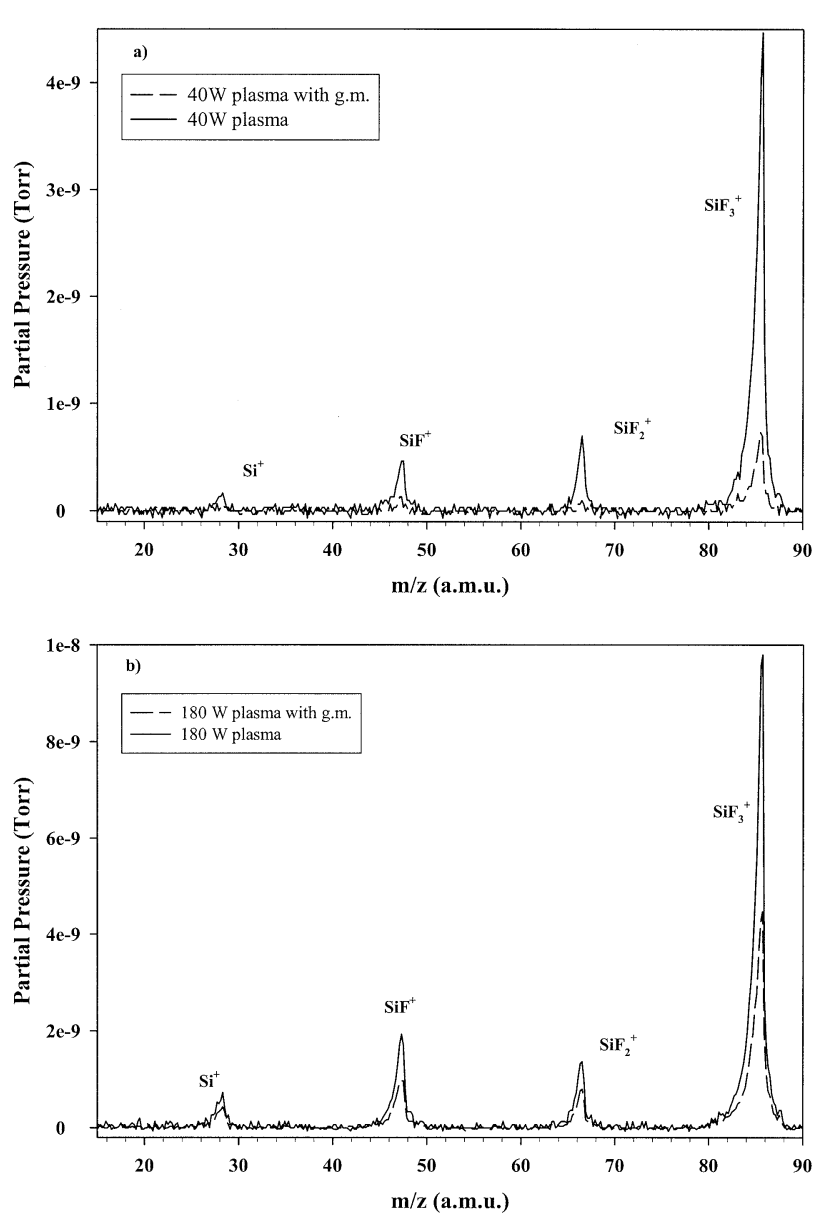

Figure 1. Experimental PI-MS data for nascent ions in (a) a $40 \mathrm{~W}$ SiF4 plasma and (b) a $170 \mathrm{~W}$ plasma from 15 to $90 \mathrm{amu}$. Mass signals appear at $28,47,66$, and $85 \mathrm{amu}$, corresponding to $\mathrm{Si}^{+}$, $\mathrm{SiF}^{+}, \mathrm{SiF}_{2}^{+}$, and $\mathrm{SiF}_{3}^{+}$respectively. Also shown are the same spectra taken with the grounded mesh placed in the path of the molecular beam (dashed lines).

is controlled primarily through the amount of diluent added. For example, $\mathrm{SiF}_{4} / \mathrm{O}_{2}$ plasmas with a high $\mathrm{O}_{2}$ concentration can deposit high quality fluorinated silicon dioxide $\left(\mathrm{F}-\mathrm{SiO}_{2}\right)$, an important low $\mathrm{k}$ dielectric material [3, 27]. Likewise, $\mathrm{SiF}_{4} / \mathrm{H}_{2}$ plasmas are used to deposit amorphous hydrogenated, fluorinated $\mathrm{Si}$ (a-Si: $\mathrm{H}, \mathrm{F})$, a potential solar cell material [28, 29]. Deposition mechanisms in these systems are not fully understood, and a more detailed understanding of both etching and deposition processes in $\mathrm{SiF}_{4}$-based plasmas is needed. For our purposes, the $\mathrm{SiF}_{4}$ system also serves as a model for other F-atom based etching systems.

Insight into the relationship between gas-phase neutral and ionic species can be gleaned from the PI-MS data of the $\mathrm{SiF}_{4}$ plasma molecular beam. Figure 1 shows the PI-MS spectra of nascent ions for $40 \mathrm{~W}$ and $180 \mathrm{~W}$ $\mathrm{SiF}_{4}$ plasma molecular beams. The only peaks in both spectra correspond to $\mathrm{SiF}_{\mathrm{x}}^{+}$ions $(\mathrm{x}=0-3)$, with $\mathrm{SiF}_{3}^{+}$ $(m / z=85)$ dominating the spectra at both $P$. When the ionizer is turned on, we observe $\mathrm{SiF}_{4}^{+}$, higher order silanes (i.e., $\mathrm{Si}_{2} \mathrm{~F}_{5}^{+}$), and small amounts of $\mathrm{HF}^{+}$and $\mathrm{F}_{2}^{+}$in the mass spectra [30]. Also shown in Figure 1 are the nascent ion spectra for the same plasmas with the grounded mesh in the path of the molecular beam. Although these spectra have not been absolutely calibrated, it is clear that the signal intensities of all ions in the g.m. spectra are significantly reduced at both $P$, indicating we have removed the majority of the charged species. For $\mathrm{SiF}_{3}^{+}, \sim 25 \%$ of these ions are penetrating the g.m. at the higher power $(P=180 \mathrm{~W})$, and $\sim 10 \%$ are transmitted at the lower power. For the lower mass ions, essentially all of the ions are removed at the lower power with only $\sim 5 \%$ transmitting through the grounded mesh. In other plasma systems, we have shown that $>99 \%$ of the ions can be removed using the grounded mesh [31].

Armentrout and coworkers have examined a number of ion-molecule reactions using $\mathrm{SiF}_{4}$ as the neutral gas $[32,33]$. In general, the rare gas ions $\left(\mathrm{He}^{+}, \mathrm{Ne}^{+}\right.$, $\mathrm{Ar}^{+}$, and $\left.\mathrm{Kr}^{+}\right)$and $\mathrm{Si}^{+}$produce $\mathrm{SiF}_{\mathrm{x}}^{+}$ions $(\mathrm{x}=0-3)$, with $\mathrm{SiF}_{4}^{+}$only being produced in the $\mathrm{Ar}^{+}$system [32-34]. No disilicon species are observed in the $\mathrm{Si}^{+}$system [33]. Dissociative charge transfer reactions are also seen in the reactions of $\mathrm{O}^{+}, \mathrm{O}_{2}^{+}, \mathrm{N}^{+}$, and $\mathrm{N}_{2}^{+}$with $\mathrm{SiF}_{4}[34,35]$, although $\mathrm{SiOF}^{+}$and $\mathrm{SiOF}_{2}^{+}$are formed in the reaction with $\mathrm{O}_{2}^{+}$[35], and $\mathrm{SiF}_{3} \mathrm{~N}_{2}^{+}$is observed in the reaction with $\mathrm{N}_{2}^{+}$[34]. In all of these systems, however, the dominant products are either $\mathrm{SiF}^{+}\left(\mathrm{Ne}^{+}\right.$and $\mathrm{He}^{+}$at energies above $20 \mathrm{eV}$ and $\mathrm{Si}^{+}$at all kinetic energies) or $\mathrm{SiF}_{3}^{+}\left(\mathrm{Ar}^{+}, \mathrm{Kr}^{+}, \mathrm{O}^{+}, \mathrm{O}_{2}^{+}, \mathrm{N}^{+}, \mathrm{N}_{2}^{+}\right)$. In our PI-MS data, we find that $\mathrm{SiF}_{3}^{+}$dominates the nascent ion spectra at all $P$. This is also true for plasmas where $\mathrm{O}_{2}$ was added to the gas flow $(0-90 \%)$ [36]. In the $\mathrm{O}_{2}$ containing plasmas, small amounts of $\mathrm{SiOF}^{+}$are also formed, similar to what was observed in the GIBMS data [35]. Also similar to what was seen in the GIBMS data, we do not observe formation of $\mathrm{Si}_{2} \mathrm{~F}_{\mathrm{y}}^{+}$species, although neutral disilicon species are clearly being formed. The absence of these species in the single-collision GIBMS experiments suggest that polymerization of silicon in $\mathrm{SiF}_{4}$ does not proceed through ion-molecule reactions [33]. Further support for this comes from the early work of Senzer and Lampe who studied the thermal energy reactions of $\mathrm{D}_{2}^{+}, \mathrm{D}_{3}^{+}, \mathrm{SiF}^{+}$and $\mathrm{SiF}_{3}^{+}$with $\mathrm{SiF}_{4}$ [37]. From their results which showed the majority of these reactions are endothermic, the authors suggested that the ionic distribution in $\mathrm{SiF}_{4}$ discharges should be largely determined by dissociative ionization processes resulting from electron impact reactions, not from ion-molecule reactions.

\section{$\mathrm{SiF}_{2}$ Surface Interactions in $\mathrm{SiF}_{4}$ Plasmas}

As noted above, $\mathrm{SiF}_{4}$ plasmas can be used to either etch Si-based materials or to deposit Si-containing thin films, depending on the plasma conditions and gas composition. With relatively high power $100 \% \mathrm{SiF}_{4}$ plasmas (i.e., $P>80 \mathrm{~W}$ ), etching is the dominant plasma process with no discernable film deposition. IRIS results for $\mathrm{SiF}_{2}$ interacting with a Si substrate under etching conditions $\left(P=170 \mathrm{~W}, 30 \mathrm{sccm} \mathrm{SiF}_{4}\right)$ are shown in a series of ICCD images, Figure 2. The LIF signal from $\mathrm{SiF}_{2}$ radicals in 

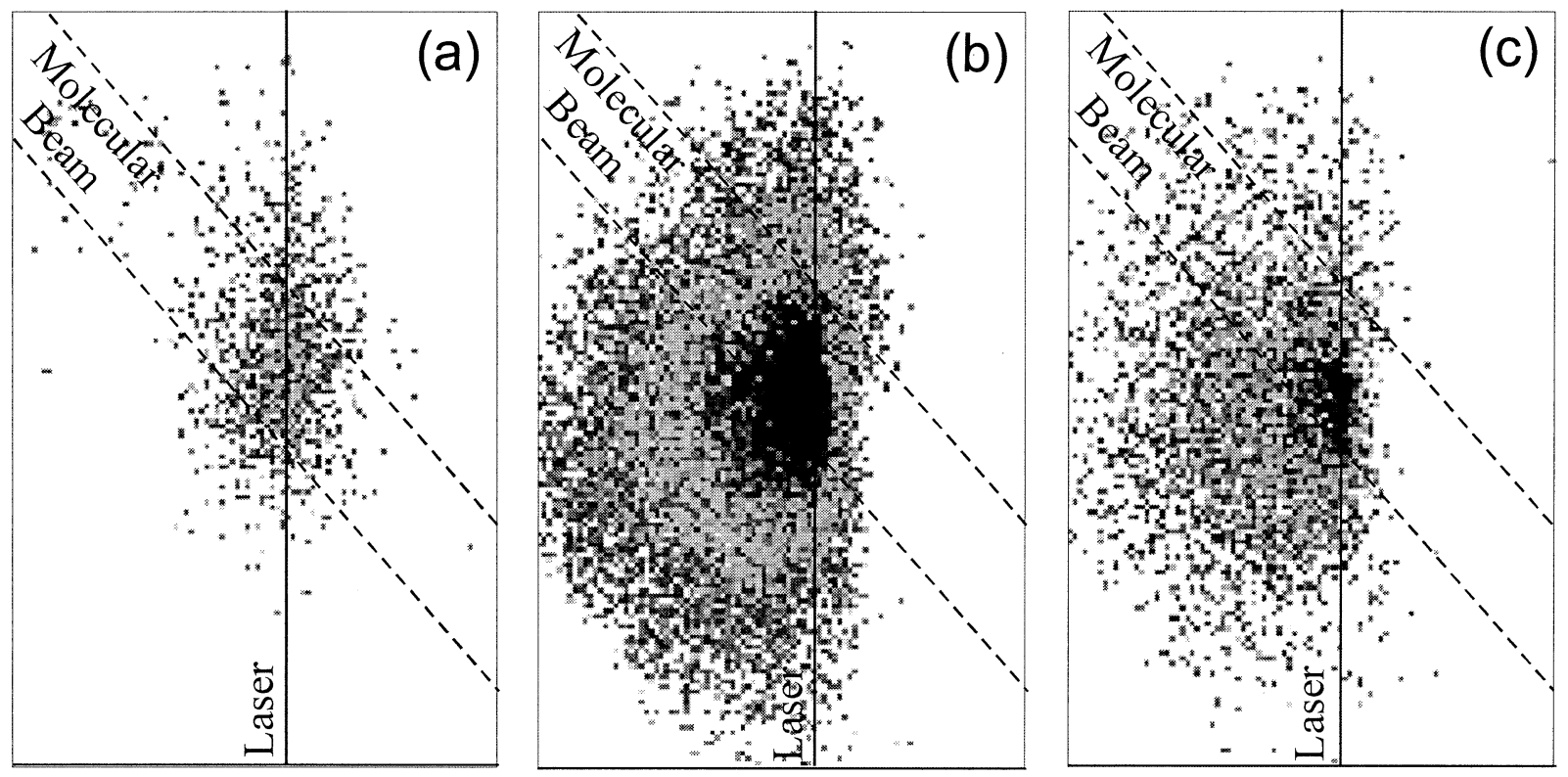

Figure 2. Spatially resolved two-dimensional ICCD images of the LIF signal for SiF2 (a) in a 100\% $\mathrm{SiF} 4$ plasma molecular beam $(P=170 \mathrm{~W}, 30 \mathrm{sccm} \mathrm{SiF} 4)$ and $(\mathbf{b})$ with a $300 \mathrm{~K} \mathrm{Si}(100)$ substrate rotated into the path of the molecular beam at a laser-surface distance of $3 \mathrm{~mm}$. The difference between the images shown in (a) and (b) is shown in (c), corresponding to $\mathrm{SiF}_{2}$ radicals scattering from the surface. LIF signals with the highest intensity appear as the darkest regions in the images. Dashed and solid lines indicate the location of the molecular beam and laser, respectively.

the incident beam is shown in Figure $2 a$. Figure $2 b$ is the LIF signal for both incident and scattered $\mathrm{SiF}_{2}$ radicals obtained with a Si substrate rotated into the path of the molecular beam. Figure $2 \mathrm{c}$ is the difference between Figure $2 b$ and Figure $2 a$, representing signal from only $\mathrm{SiF}_{2}$ molecules desorbing from the substrate. It is clear from this image that a substantial amount of $\mathrm{SiF}_{2}$ is generated from the silicon substrate under these conditions. This result was somewhat expected as $\mathrm{SiF}_{2}$ is a known product of $\mathrm{F}$ atom etching of silicon.

Figure 3 shows the 1-D cross sections corresponding to the images in Figure 2a (incident $\mathrm{SiF}_{2}$ ) and Figure 2c (desorbing $\mathrm{SiF}_{2}$ ). Simulated curves for the incident beam and desorbing molecules with $S=2.70$ are also shown in Figure 3. Averaging several data sets taken over a period of 9 months yields $S=2.78 \pm 0.08$. As noted above, an $S$ value greater than unity indicates that surface production of $\mathrm{SiF}_{2}$ contributes to the observed signal. It should be noted that this value does not account for any translational or rotational energy changes that may occur in the distribution of incident versus scattered molecules. IRIS experiments measure relative densities of $\mathrm{SiF}_{2}$ in the molecular beam versus those desorbing from the surface. If the two populations have different velocities, the relative densities in the laser beam will be different. This can be accounted for by scaling $S$ with the ratio of the incident velocity to the velocity of the scattered molecules. Preliminary results for measurements of the velocity of $\mathrm{SiF}_{2}$ in the $\mathrm{SiF}_{4}$ molecular beam indicate $\Theta_{\mathrm{T}}\left(\mathrm{SiF}_{2}\right) \sim 500 \mathrm{~K}$ at $P=170 \mathrm{~W}$ [36]. If the $\mathrm{SiF}_{2}$ adsorbs and thermally equilibrates with the surface before desorbing, the scattered $\mathrm{SiF}_{2}$ are expected to have $\Theta_{\mathrm{T}} \sim \mathrm{T}_{\mathrm{S}}=300 \mathrm{~K}$. This leads to a correction factor of 1.28 , which results in a corrected $S$ value of $3.55 \pm 0.08$. Previous IRIS data for $\mathrm{NH}_{2}$ suggest

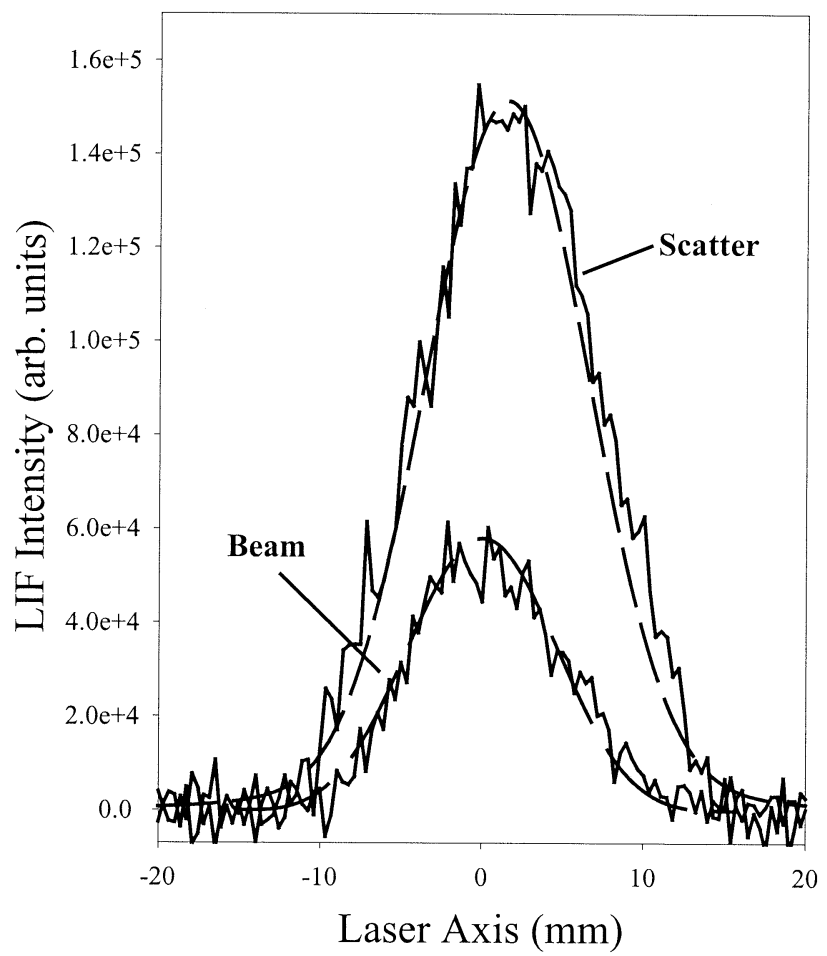

Figure 3. Cross-sectional data for the $\mathrm{SiF}_{2} \mathrm{LIF}$ data shown in Figures 2a and 2c. Dashed lines represent the simulated curves from the geometric model with $S=2.70$. The laser-surface distance is $3.0 \mathrm{~mm}$. 
Table 1. Scatter Coefficient data for $\mathrm{SiF}_{2}$ using $\mathrm{SiF}_{4}$ plasmas

\begin{tabular}{|c|c|c|c|c|}
\hline Flow Conditions & Power (W) & Ion Perturbation ${ }^{a}$ & $S$ Value & Corrected $S$ Value \\
\hline \multirow{4}{*}{15 sccm SiF 4} & 20 & None & $0.20 \pm 0.02$ & $0.26 \pm 0.02$ \\
\hline & 40 & None & $0.32 \pm 0.02$ & $0.41 \pm 0.02$ \\
\hline & 80 & None & $2.79 \pm 0.13$ & $3.57 \pm 0.13$ \\
\hline & 170 & None & $3.08 \pm 0.11$ & $3.94 \pm 0.11$ \\
\hline \multirow[t]{4}{*}{$30 \mathrm{sccm} \mathrm{SiF} 4$} & 20 & None & $0.70 \pm 0.03$ & $0.89 \pm 0.03$ \\
\hline & 40 & None & $0.93 \pm 0.02$ & $1.19 \pm 0.02$ \\
\hline & 80 & None & $2.36 \pm 0.08$ & $3.02 \pm 0.08$ \\
\hline & 170 & None & $2.78 \pm 0.08$ & $3.55 \pm 0.08$ \\
\hline \multirow[t]{3}{*}{30 sccm $\mathrm{SiF}_{4}$} & 170 & g.m. & $2.00 \pm 0.14$ & $2.56 \pm 0.14$ \\
\hline & 170 & $+200 V_{d c}$ & $2.43 \pm 0.04$ & $3.11 \pm 0.04$ \\
\hline & 170 & $-200 V_{d c}$ & $3.03 \pm 0.04$ & $3.87 \pm 0.04$ \\
\hline \multirow[t]{4}{*}{$90: 10 \mathrm{SiF}_{4}: \mathrm{H}_{2}$} & 170 & None & $1.48 \pm 0.10$ & $1.89 \pm 0.10$ \\
\hline & 170 & g.m. & $1.30 \pm 0.20$ & $1.66 \pm 0.20$ \\
\hline & 170 & $+200 \mathrm{~V}_{\mathrm{dc}}$ & $1.31 \pm 0.05$ & $1.67 \pm 0.05$ \\
\hline & 170 & $-200 V_{d c}$ & $2.32 \pm 0.04$ & $2.97 \pm 0.04$ \\
\hline
\end{tabular}

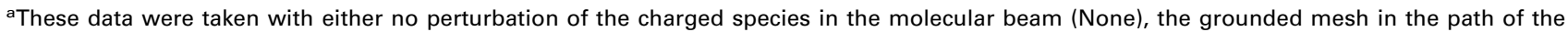
molecular beam (g.m.), or $\pm 200 \mathrm{~V}_{\mathrm{dc}}$ biasing of the Si substrate.

bThese values were calculated assuming $\Theta_{T}\left(\mathrm{SiF}_{2}\right)$ in the incident beam was $500 \mathrm{~K}$ and $\Theta_{\mathrm{T}}\left(\mathrm{SiF}_{2}\right)$ of desorbing molecules was characterized by the substrate temperature of $300 \mathrm{~K}$. Error bars represent only the error in the measured $S$ values.

that $\Theta_{\mathrm{T}}$ of surface generated species in the presence of ion bombardment can be higher than the substrate temperature [20]. Thus, the value of $3.55 \pm 0.08$ should be considered an upper limit to $S$ under these conditions.

Table 1 lists the measured $S$ values along with the corrected $S$ values (assuming $\Theta_{\mathrm{T}}\left(\mathrm{SiF}_{2}\right)=500 \mathrm{~K}$ for the incident species) for $\mathrm{SiF}_{2}$ from $100 \% \mathrm{SiF}_{4}$ plasmas as a function of $P$. Very little $\mathrm{SiF}_{2}$ scatter is observed at $P=$ 20 and $40 \mathrm{~W}$, with $S<1$ in most cases. Thus, $\mathrm{SiF}_{2}$ is being consumed at the surface, with surface reaction probabilities, $R$, as high as $\sim 0.7$. In contrast, at $P>40$ $\mathrm{W}$, surface generation of $\operatorname{SiF}_{2}(S>1)$ is measured, suggesting that increasing the applied rf power significantly increases etch probability. Interestingly, our PI-MS data indicate there are also significantly more ions produced at the higher rf powers, which is a common phenomenon in many plasma systems [38].

There are several possible mechanisms by which $\mathrm{SiF}_{2}$ can be generated at the surface. The most obvious of these is $\mathrm{F}$ atom etching, which has been reported to produce both $\mathrm{SiF}_{2}$ and $\mathrm{SiF}_{4}$ as etch products [26]. Another possibility is an enhancement of $\mathrm{SiF}_{2}$ scatter (and Si etching) by ion-induced sputtering. The degree to which ion bombardment affects surface production of $\mathrm{SiF}_{2}$ in IRIS experiments was investigated by two methods. First, the $\mathrm{SiF}_{2}$ surface interactions were measured using a biased silicon substrate to perturb charged species as they approach the surface. With $+200 \mathrm{~V}_{\mathrm{dc}}$ biasing, positively charged species are repelled such that ion bombardment of the surface becomes negligible. In contrast, $-200 \mathrm{~V}_{\mathrm{dc}}$ biasing accelerates the positively charged species in the molecular beam toward the surface. Second, a grounded wire mesh (g.m.) was placed on the defining slit of the molecular beam to remove the majority of charged species from the molecular beam. As shown in Figure 1, at least $75 \%$ of the charged species are removed from the molecular beam when the grounded mesh is used.
Table 1 lists $S$ values for $\mathrm{SiF}_{2}$ radicals interacting with biased Si substrates and with the g.m. in the molecular beam for $170 \mathrm{~W}$ plasmas with two different source compositions, $100 \% \mathrm{SiF}_{4}$ and 90:10 $\mathrm{SiF}_{4}: \mathrm{H}_{2}$. As noted above, the addition of $\mathrm{H}_{2}$ to the plasma results in deposition of a-Si:H,F films, thereby taking the plasma from the etching to the deposition regime. For purposes of comparison, we define $\delta S c$ as the difference between $S$ measured with no perturbation of the charged species and $S$ measured with either biased substrates $\left(S_{\text {bias }}\right)$ or with the g.m. $\left(S_{\text {g.m. }}\right)$. Thus, $\delta S c=S-S_{\text {bias }}$ or $\delta S c=S-S_{g . m}$. Under all feed gas conditions, $+200 \mathrm{~V}_{\mathrm{dc}}$ biasing yields a decrease in $S$ values, as does using the g.m., resulting in positive $\delta S c$ values ranging from $\delta S c=0.22 \pm 0.11$ for a $10 \% \mathrm{H}_{2}$ plasma $(P=$ $170 \mathrm{~W})$ with the $+200 \mathrm{~V}_{\mathrm{dc}}$ biased substrate to $\delta S \mathrm{c}=$ $0.99 \pm 0.16$ for the $100 \% \mathrm{SiF}_{4}$ plasma $(P=170 \mathrm{~W})$ with the grounded mesh. With $-200 \mathrm{~V}_{\mathrm{dc}}$ biasing, $\delta S c$ values were negative, with $\delta S c=-1.08 \pm 0.11$ for the $10 \% \mathrm{H}_{2}$ plasma and $\delta S c=-0.32 \pm 0.09$ for the $100 \%$ $\mathrm{SiF}_{4}$ plasma, suggesting more $\mathrm{SiF}_{2}$ desorb when ions are accelerated toward the substrate. Thus, changes in the $\mathrm{SiF}_{2}$ scatter with ion perturbation behave as expected if ion bombardment indeed enhanced desorption of $\mathrm{SiF}_{2}$. Similar ion effects have also been observed for $\mathrm{CF}_{2}$ in a variety of FCPs [39], and for $\mathrm{NH}_{2}$ in $\mathrm{NH}_{3}$ plasmas $[19,20]$.

As the data clearly demonstrate that ion-induced mechanisms contribute to the $\mathrm{SiF}_{2}$ surface generation, it is instructive to consider these mechanisms in detail. Ion bombardment has been reported to enhance the silicon etching process at high $P[40,41]$, and radical-ion beam experiments also indicate that the number of radicals chemically sputtered by ions can be much greater than unity in the presence of F atoms [42, 43]. Our data support this latter observation, as there is a significant increase in $\mathrm{SiF}_{2}$ scatter as the $\mathrm{SiF}_{4}$ flow rate is 
increased. This could be the result of an increase in F atom concentration in the higher pressure plasmas.

Ion-induced generation of $\mathrm{SiF}_{2}$ may occur by a variety of pathways, three of which are given in eq 1-3,

$$
\begin{aligned}
& \mathrm{I}^{+}+\mathrm{SiF}_{2} \text { (ads) } \rightarrow \mathrm{SiF}_{2}(\mathrm{~g})+\mathrm{I} \\
& \mathrm{SiF}_{2}^{+}(\mathrm{g})+{ }^{*} \rightarrow \mathrm{SiF}_{2} \text { (ads) } \rightarrow \mathrm{SiF}_{2}(\mathrm{~g}) \\
& \mathrm{SiF}_{3}^{+}(\mathrm{g})+2^{*} \rightarrow \mathrm{SiF}_{2} \text { (ads) }+\mathrm{F}(\text { ads }) \rightarrow \mathrm{SiF}_{2}(\mathrm{~g})+\mathrm{F}(\text { ads })
\end{aligned}
$$

where * represents surface active sites and $\mathrm{I}^{+}$represents any plasma ion. Reaction 1 can be considered as a general ion sputtering mechanism, wherein any energetic ion that impinges upon the surface may impart enough energy to allow $\mathrm{SiF}_{2}$ desorption. Likewise, surface neutralization, Process 2, or neutralization and dissociation, Process 3, may also promote surface generation of $\mathrm{SiF}_{2}$. In all cases, preventing ions from impinging upon the surface would result in a decrease in the amount of $\mathrm{SiF}_{2}$ scatter. This is indeed what we observe in our $+200 \mathrm{~V}_{\mathrm{dc}}$ biasing experiments and in our g.m. experiments, Table 1. In contrast, when ions are accelerated toward the surface in the $-200 \mathrm{~V}_{\mathrm{dc}}$ biasing experiments, the amount of scatter increases significantly. These predictable changes in scatter confirm that the presence of positive ions notably enhances surface generation of $\mathrm{SiF}_{2}$.

Coburn and Winters have measured the effects of $\mathrm{Ar}^{+}$bombardment of the $\mathrm{SiF}_{\mathrm{x}}$ adlayer [26]. In the absence of ions, $\mathrm{SiF}_{3}$ is the major adlayer species. Under $\mathrm{Ar}^{+}$bombardment $(450 \mathrm{eV})$, however, $\mathrm{SiF}_{2}$ becomes the dominant adlayer moiety. Our IRIS results are consistent with these results as $\mathrm{SiF}_{2}$ desorption is significantly enhanced by energetic ions. Also consistent with these results is our PI-MS data and our data for relative ion densities measured in the IRIS instrument, which show an $\sim 5$-fold increase in ion density from 25 to $170 \mathrm{~W}$ [30].

$\mathrm{SiF}_{2}$ IRIS measurements at the lowest $P$ indicate that $\mathrm{SiF}_{2}$ is consumed at the surface, which may be accounted for by examining literature data on the substrate temperature dependence of F-atom etching of $\mathrm{Si}$ and the effects of ion bombardment. Using a $\mathrm{XeF}_{2}$ molecular beam, Coburn and Winters [26] have identified $\mathrm{SiF}_{4}$ as the primary etch product of $\mathrm{F}$ atom etching on $\mathrm{Si}$ at $\mathrm{T}_{\mathrm{S}}<600 \mathrm{~K}$, whereas $\mathrm{SiF}_{2}$ becomes predominate at $\mathrm{T}_{\mathrm{S}}>600 \mathrm{~K}$. In our experiments at low $P$, there may be insufficient energy to desorb significant amounts of $\mathrm{SiF}_{2}$ or the F-atom concentration may be too low to produce significant quantities of $\mathrm{SiF}_{2}$ or $\mathrm{SiF}_{4}$. We have explored this by measuring $S$ as a function of $\mathrm{T}_{\mathrm{S}}$ and find that $S\left(\mathrm{SiF}_{2}\right)$ increases by approximately a factor of 2 for a 40 $\mathrm{W}$ plasma at $\mathrm{T}_{\mathrm{S}}=700 \mathrm{~K}[44]$. Thus, our preliminary data suggest that under these plasma conditions, the low levels of $\mathrm{SiF}_{2}$ desorption are more likely a function of the available energy rather than the availability of $\mathrm{F}$ atoms.
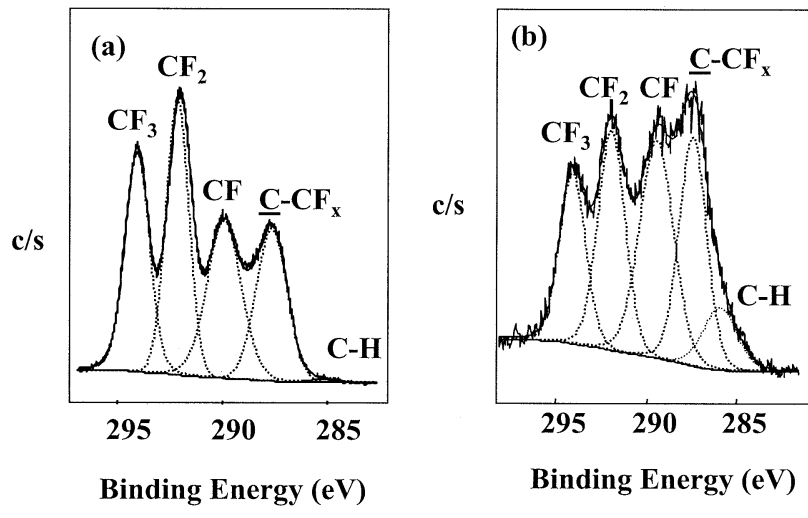

Figure 4. XPS C1s spectra for fluorocarbon films deposited $8 \mathrm{~cm}$ downstream from the plasma glow in $\mathrm{CW} 50 \mathrm{~W}$ fluorocarbon plasmas: (a) $\mathrm{C}_{3} \mathrm{~F}_{8}$ and (b) $\mathrm{C}_{4} \mathrm{~F}_{8}$.

\section{Fluorocarbon Plasmas}

Over the past 5 years, we have studied a variety of fluorocarbon systems, including $\mathrm{C}_{2} \mathrm{~F}_{6}, \mathrm{C}_{2} \mathrm{~F}_{6} / \mathrm{H}_{2}, \mathrm{CHF}_{3}$ [45], hexafluoropropylene oxide (HFPO) [46], $\mathrm{C}_{6} \mathrm{~F}_{6}$, and 1,2,4- $\mathrm{C}_{6} \mathrm{H}_{3} \mathrm{~F}_{3}$ plasmas [47]. Most recently, we have focused on $\mathrm{C}_{3} \mathrm{~F}_{8}$ and $\mathrm{C}_{4} \mathrm{~F}_{8}$ plasmas as these systems are finding increased use in the microelectronics industry because of their lower global warming potentials [48]. Many of the theoretical $[15,16]$ and experimental $[8,9$, 49 ] studies of FCP's have shown that plasma ions have considerable influence over resulting film chemistries. Recently, we have shown that ions can also significantly influence molecule-surface interactions in these systems [39].

It is well known that exposure to ions and other high energy plasma species can lead to extensive cross linking in deposited polymeric materials [4]. Downstream depositions are one approach to limiting the substrate's exposure to charged species. Figure 4 shows $\mathrm{C}_{1 \mathrm{~s}}$ XPS spectra of films deposited $8 \mathrm{~cm}$ downstream from the plasma glow in $50 \mathrm{~W} \mathrm{C}_{3} \mathrm{~F}_{8}$ and $\mathrm{C}_{4} \mathrm{~F}_{8}$ plasmas. Under the same deposition conditions, films formed in $\mathrm{C}_{3} \mathrm{~F}_{8}$ plasmas are less cross-linked (defined as \% $\mathrm{CF}+$ $\left.\% \mathrm{C}-\mathrm{CF}_{\mathrm{x}}+\% \mathrm{C}-\mathrm{H}\right)$, with higher $\mathrm{CF}_{2}$ content and $\mathrm{F} / \mathrm{C}$ ratios than those deposited in $\mathrm{C}_{4} \mathrm{~F}_{8}$ plasmas. We have also found that films deposited even further downstream (i.e., $28 \mathrm{~cm}$ from the glow) have significantly lower cross-linking as do films deposited at lower applied rf powers [22, 46].

Another approach to limiting the depositing film's exposure to charged species is to use pulsed plasmas [50] which have been shown to reduce trapped radicals in the depositing films, lower deposition surface temperatures, and decrease ion and UV flux to the surface. Consequently, greater control over the resulting film chemistry is achieved, with higher retention of the monomer functionalities [47]. Figure 5 shows $C_{1 \mathrm{~s}}$ XPS spectra for films deposited $8 \mathrm{~cm}$ downstream in pulsed $\mathrm{C}_{3} \mathrm{~F}_{8}$ at two different duty cycles, where duty cycle is defined as the ratio of on time to total cycle time. Clearly, decreasing the duty cycle leads to films with 

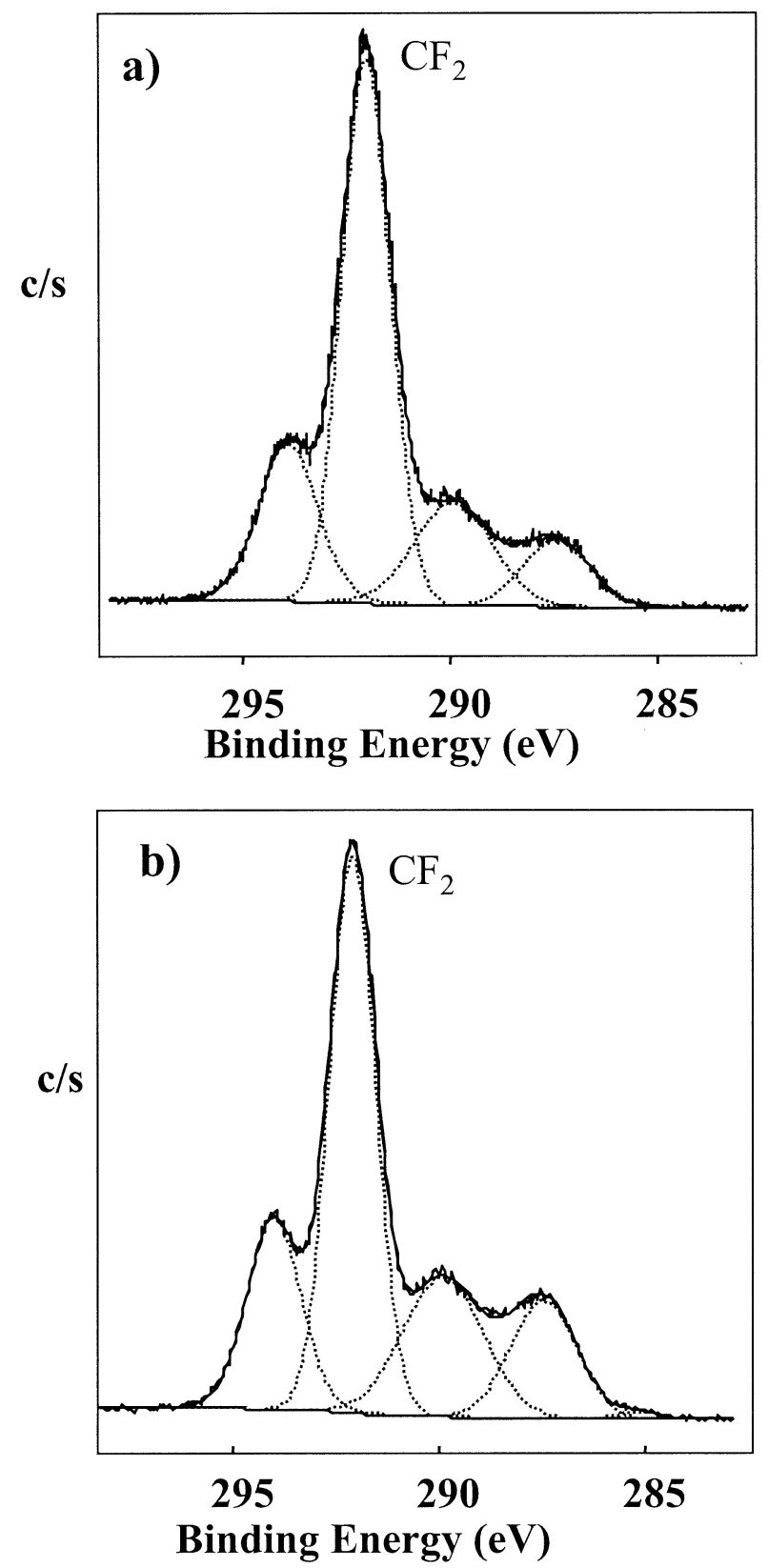

Figure 5. XPS $C_{1 \mathrm{~s}}$ spectra for fluorocarbon films deposited $8 \mathrm{~cm}$ downstream from the plasma glow in pulsed $\mathrm{C}_{3} \mathrm{~F}_{8}$ with (a) $3 \%$ and (b) $16 \%$ duty cycle, where duty cycle is defined as the ratio of on time to total cycle time. Peak applied rf power was $300 \mathrm{~W}$.

higher $\mathrm{CF}_{2}$ content and lower cross-linking. Moreover, these materials have less cross-linking than films deposited in CW plasmas of equivalent power at the same distance downstream. Thus, reduction of ion bombardment significantly changes the composition of the deposited fluorocarbon polymer film, and leads to a more ordered polymeric structure.

\section{$\mathrm{CF}_{2}$ Surface Interactions in $\mathrm{C}_{3} F_{8}$ and $\mathrm{C}_{4} F_{8}$ Plasmas}

As noted above, the presence of ions also strongly affects the surface interactions of plasma species in fluorocarbon systems. Figure 6 shows IRIS images for the difluorocarbene molecule $\left(\mathrm{CF}_{2}\right)$ in a $100 \% \mathrm{C}_{4} \mathrm{~F}_{8}$ plasma $(100 \mathrm{~W})$ interacting with a $\mathrm{Si}(100)$ substrate. Similar to the $\mathrm{SiF}_{2}$ results shown in Figure 2, there is a significant amount of $\mathrm{CF}_{2}$ desorbing from the substrate. Under these conditions, an amorphous fluorocarbon polymer is being deposited on the substrate surface, similar to that shown in Figure $4 \mathrm{~b}$. Figure 7 contains the 1-D cross sections and modeled fits to the data yielding $S=2.65 \pm 0.05$, for this particular data set, and an overall value from several data sets of $S=2.58 \pm 0.03$ (This value is not corrected for differences in velocity distributions between the incident and desorbing $\mathrm{CF}_{2}$ populations). This indicates there is a considerable amount of $\mathrm{CF}_{2}$ produced at the surface during film deposition. Although we have observed surface generation of $\mathrm{CF}_{2}$ in other FCPs, including $\mathrm{CHF}_{3}$ and $\mathrm{C}_{2} \mathrm{~F}_{6}$ $[39,51]$, this is one of the largest scatter coefficients we have measured for $\mathrm{CF}_{2}$.

Table 2 lists scatter values for $\mathrm{CF}_{2}$ in $\mathrm{C}_{4} \mathrm{~F}_{8}$ and $\mathrm{C}_{3} \mathrm{~F}_{8}$ plasmas at two powers $(P=50$ and $100 \mathrm{~W})$, along with results acquired using the grounded mesh in the path of the molecular beam. In these systems, the grounded mesh removes $\sim 90 \%$ and $\sim 75 \%$ of the charged species at 50 and $100 \mathrm{~W}$ applied rf power, respectively. As with $\mathrm{SiF}_{2}$ in the $\mathrm{SiF}_{4}$ system, removal of ions results in a significant decrease in the scatter, with the largest difference, $\delta S c=1.51 \pm 0.08$, occurring with the $100 \mathrm{~W}$ $\mathrm{C}_{4} \mathrm{~F}_{8}$ plasma. Also similar to the $\mathrm{SiF}_{2}$ system, we anticipate there are several possible mechanisms that could contribute to the observed surface generation of $\mathrm{CF}_{2}$ radicals and have discussed many of these previously [39]. The ion-mediated mechanisms that may be contributing to the observed scatter are analogous to those given above in eq 1-3 for $\mathrm{SiF}_{2}$. Here, however, we believe that ion-sputtering of the deposited fluorocarbon layer, eq 4 ,

$$
\mathrm{I}^{+}+-\left(\mathrm{CF}_{\mathrm{x}}\right)_{\mathrm{n}}-\rightarrow \mathrm{CF}_{2}(\mathrm{~g})+-\left(\mathrm{CF}_{\mathrm{x}}\right)_{\mathrm{n}-1}-+\mathrm{I}
$$

may be a significant contributor. Although possibly unrelated, the film deposition rates in these systems can be extremely high (up to $1500 \AA / \mathrm{min}$ ), such that there is a considerable amount of material available for sputtering. In contrast, in the $\mathrm{SiF}_{4}$ system, no film deposition occurs such that the amount of ablated material is strongly dependent on the formation of $\mathrm{SiF}_{\mathrm{x}}$ surface moieties.

As noted in the Introduction, experimental and theoretical work on ion-surface interactions in fluorocarbon plasmas has shown that the ion-to-neutral flux ratio is an important factor in determining if either net deposition or net etching occurs at the substrate. Moreover, ion beam experiments for $\mathrm{CF}_{\mathrm{x}}^{+}$ions $(\mathrm{x}=1-3)$ have shown that both etching and deposition are sensitive to the $\mathrm{F} / \mathrm{C}$ ratio as well as the incident ion energy $[8,9,14]$. Molecular dynamics simulations by Graves and coworkers have also focused on $\mathrm{CF}_{\mathrm{x}}^{+}(\mathrm{x}=1-3)$ ion 


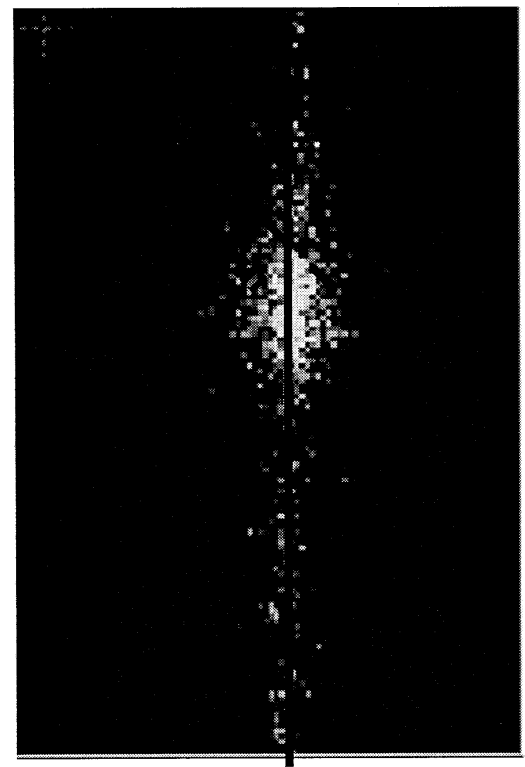

(a)

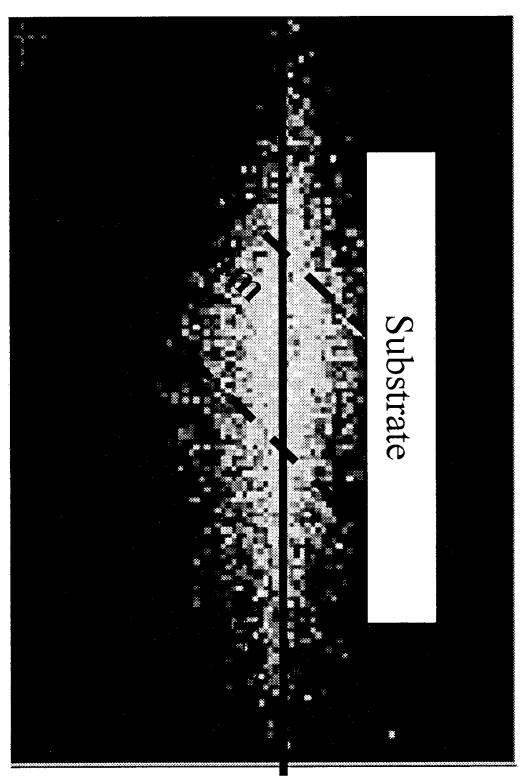

(b)

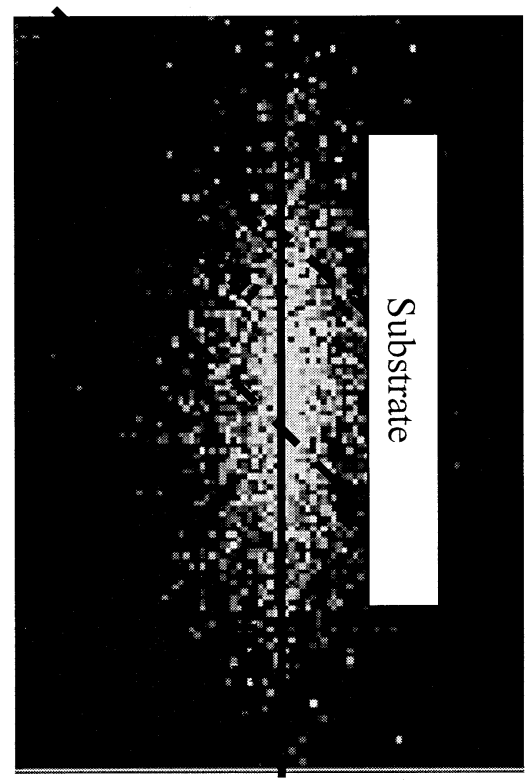

(c)

Figure 6. Spatially resolved two-dimensional ICCD images of the LIF signal for $\mathrm{CF}_{2}(\mathbf{a})$ in a $100 \%$ $\mathrm{C}_{4} \mathrm{~F}_{8}$ plasma molecular beam $(P=100 \mathrm{~W})$ and $(\mathbf{b})$ with a $300 \mathrm{~K} \mathrm{Si}(100)$ substrate rotated into the path of the molecular beam at a laser-surface distance of $3 \mathrm{~mm}$. The difference between the images shown in (a) and (b) is shown in (c), corresponding to $\mathrm{CF}_{2}$ radicals scattering from the surface. LIF signals with the highest intensity appear as the lightest regions in the images. Dashed and solid lines indicate the location of the molecular beam and laser, respectively.

bombardment of Si substrates as a function of incident ion energy, $E_{i}[15,16,40]$. These studies show that $\mathrm{CF}_{3}^{+}$ ions etch $\mathrm{Si}$ through a deposited fluorocarbon layer [15]. With $\mathrm{CF}^{+}$and $\mathrm{CF}_{2}^{+}$bombardment, a fluorocarbon layer

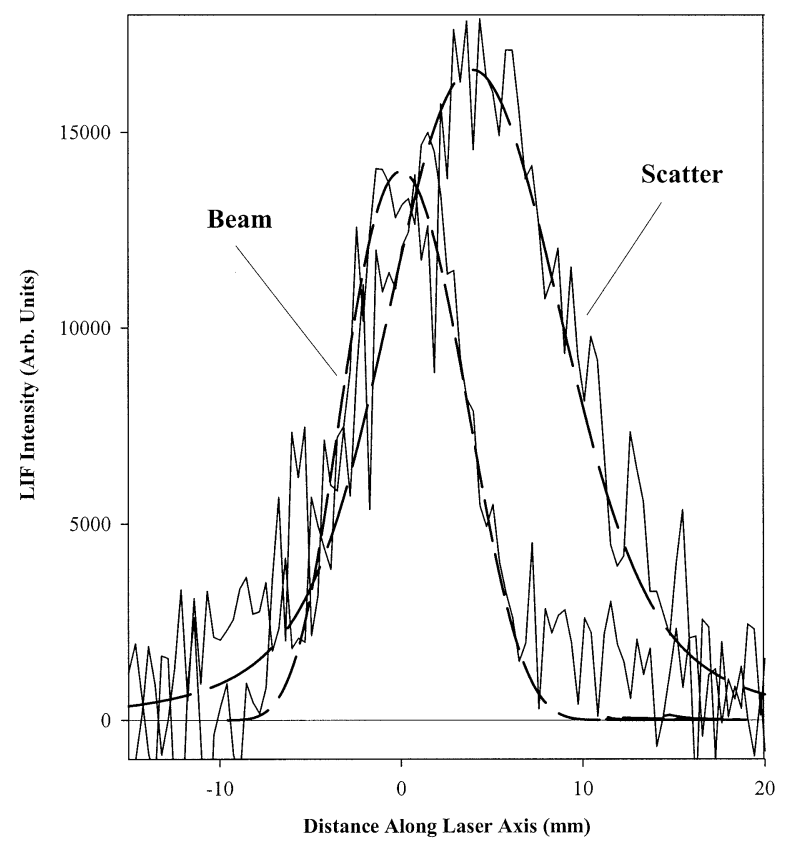

Figure 7. Cross-sectional data for the $\mathrm{CF}_{2}$ LIF data shown in Figures $6 \mathrm{a}$ and $6 \mathrm{c}$. Dashed lines represent the simulated curves from the geometric model with $S=2.65$. The laser-surface distance is $3.0 \mathrm{~mm}$. is also formed on the Si surface during the simulations, and net deposition results in the case of $\mathrm{CF}^{+}$bombardment [16]. With $\mathrm{CF}_{2}^{+}$, however, some etching of the $\mathrm{Si}$ layer occurs at the highest $\mathrm{E}_{\mathrm{i}}=200 \mathrm{eV}$ [16]. More importantly, the simulations show $\mathrm{CF}_{3}^{+}$can dissociate on $\mathrm{Si}$ substrates, creating relatively large quantities of $\mathrm{CF}_{2}$ as a product of surface dissociation, depending on $\mathrm{E}_{\mathrm{i}}$. The extent of fragmentation increases at higher incident ion energies, with greater formation of $\mathrm{CF}$ at $\mathrm{E}_{\mathrm{i}}>100 \mathrm{eV}$. Thus, we believe this process, i.e., neutralization and dissociation of $\mathrm{CF}_{3}^{+}$on the surface is likely contributing to the $\mathrm{CF}_{2}$ surface generation we observe in our IRIS experiments.

Table 2. Scatter coefficients for $\mathrm{CF}_{2}$ in $\mathrm{C}_{3} \mathrm{~F}_{8}$ and $\mathrm{C}_{4} \mathrm{~F}_{8}$ plasmas

\begin{tabular}{lrcc}
\hline Plasma & Power & Ion Perturbation $^{\mathrm{a}}$ & S Value $^{\mathrm{b}}$ \\
\hline \hline $\mathrm{C}_{3} \mathrm{~F}_{8}$ & $50 \mathrm{~W}$ & None & $1.29 \pm 0.05$ \\
& $50 \mathrm{~W}$ & g.m. & $1.02 \pm 0.09$ \\
& $100 \mathrm{~W}$ & None & $2.03 \pm 0.06$ \\
& $100 \mathrm{~W}$ & g.m. & $1.15 \pm 0.08$ \\
$\mathrm{C}_{4} \mathrm{~F}_{8}$ & $50 \mathrm{~W}$ & None & $1.69 \pm 0.03$ \\
& $50 \mathrm{~W}$ & g.m. & $1.07 \pm 0.06$ \\
& $100 \mathrm{~W}$ & None & $2.58 \pm 0.03$ \\
& $100 \mathrm{~W}$ & g.m. & $1.07 \pm 0.07$ \\
\hline
\end{tabular}

aThese data were taken with either no perturbation of the charged species in the molecular beam (None) or the grounded mesh in the path of the molecular beam (g.m.).

${ }^{b}$ Not corrected for any differences in velocity distributions between the incident and desorbing $\mathrm{CF}_{2}$ populations. 

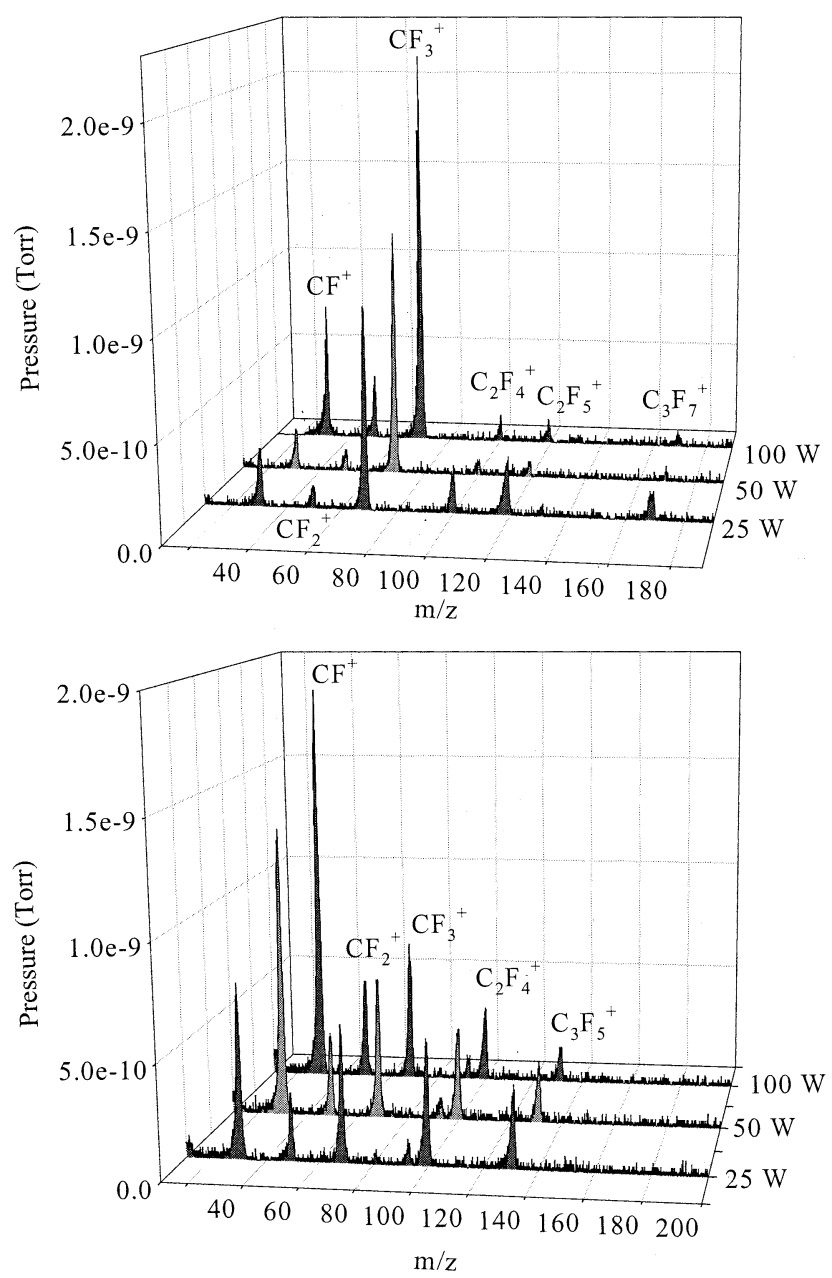

Figure 8. PI-MS data for (a) $\mathrm{C}_{3} \mathrm{~F}_{8}$ and (b) $\mathrm{C}_{4} \mathrm{~F}_{8}$ plasmas at three different applied rf powers, $P=25,50$, and $100 \mathrm{~W}$.

\section{Mass Spectrometry of Fluorocarbon Plasmas}

Given the considerable influence that plasma ions have over both the surface composition and the plasmasurface interface reactions, we have examined the gasphase chemistry, concentrating on the plasma ions and ion-molecule reactions in these systems. We have acquired PI-MS data for $\mathrm{C}_{3} \mathrm{~F}_{8}$ and $\mathrm{C}_{4} \mathrm{~F}_{8}$ plasma molecular beams. In collaboration with the Armentrout group, we have also examined ion-molecule reactions related to these systems, specifically $\mathrm{Ar}^{+}, \mathrm{O}^{+}$, and $\mathrm{O}_{2}^{+}$with $\mathrm{C}_{3} \mathrm{~F}_{8}$ [52].

Figure 8 shows PI-MS data for nascent ions in $\mathrm{C}_{3} \mathrm{~F}_{8}$ and $\mathrm{C}_{4} \mathrm{~F}_{8}$ plasma molecular beams as a function of the applied rf plasma power. $\mathrm{CF}_{3}^{+}$is the predominant ion present in $\mathrm{C}_{3} \mathrm{~F}_{8}$ plasmas, whereas $\mathrm{CF}^{+}$is predominant in the $\mathrm{C}_{4} \mathrm{~F}_{8}$ system. Again, as noted above, these mass spectra are not quantitative measures of ion densities as we have not precisely calibrated our spectrometer. They are, however, useful for both qualitative information and relative trends. Overall, increasing $P$ causes greater fragmentation of the monomer gas, resulting in higher levels of lower molecular weight $\mathrm{CF}_{\mathrm{x}}^{+}$ions and lower levels of the higher molecular weight ions. The compo-

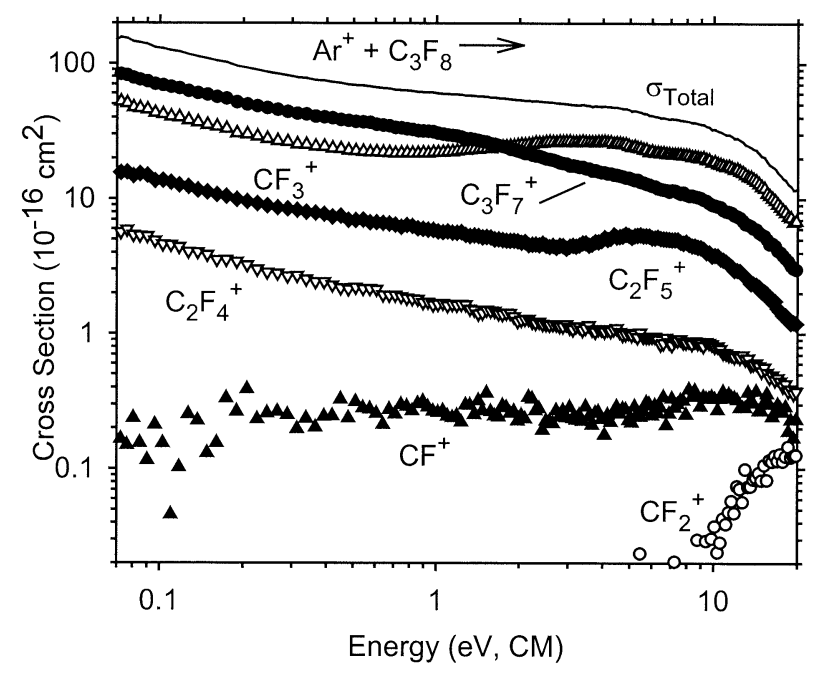

Figure 9. The variation of product cross sections with translational energy in the center-of-mass-frame for the reaction of $\mathrm{Ar}^{+}$ with $\mathrm{C}_{3} \mathrm{~F}_{8}$. The solid line shows the total cross section for the reaction.

sition of the materials deposited in these systems can also be linked to the nascent ion spectra. Specifically, as noted above, surface bombardment by the heavier ions is likely one of the contributors to formation of a more amorphous fluorocarbon film in the $\mathrm{C}_{4} \mathrm{~F}_{8}$ plasma, Figure $4 \mathrm{~b}$. Note also that deposition rates of films deposited in $\mathrm{C}_{4} \mathrm{~F}_{8}$ plasmas are 10-100 times higher than in the $\mathrm{C}_{3} \mathrm{~F}_{8}$ system, ranging from $86 \pm 8 \AA / \mathrm{min}$ for the $50 \mathrm{~W}$ $\mathrm{C}_{3} \mathrm{~F}_{8}$ plasma to $1556 \pm 45 \AA / \mathrm{min}$ for the $100 \mathrm{~W} \mathrm{C}_{4} \mathrm{~F}_{8}$ plasma.

Absolute reaction cross sections acquired with the Utah GIBMS for the reaction of $\mathrm{Ar}^{+}$with $\mathrm{C}_{3} \mathrm{~F}_{8}$ are shown in Figure 9. There are some obvious correlations that can be drawn from the data of Figures 8 and 9 . Specifically, the product ions detected in the GIBMS measurements are the same as those found in the PI-MS data. At low kinetic energies, larger molecular ions dominate the product ion spectrum, although there is also considerable $\mathrm{CF}_{3}^{+}$. At $\mathrm{E}_{\mathrm{CM}}>2 \mathrm{eV}, \mathrm{CF}_{3}^{+}$has the largest cross section, consistent with $\mathrm{CF}_{3}^{+}$being the predominant nascent ion in the $\mathrm{C}_{3} \mathrm{~F}_{8}$ plasmas at all $\mathrm{rf}$ powers. The increase in $\sigma\left(\mathrm{CF}_{3}^{+}\right)$with increasing kinetic energy demonstrates that it is a fragment of the other product ions present, specifically $\mathrm{C}_{3} \mathrm{~F}_{7}^{+}$. Under the multi-collision and energetic conditions present in a plasma, such decomposition is not surprising compared to the controlled energy and single collision environment of the GIBMS experiment.

Further studies of the reactions of different diluent gases and ions may provide insight into appropriate means to manipulate the ions present in discharges under various conditions. The present results indicate plasma conditions that could emphasize such molecular ions, which, as noted above, may be useful for identifying key ionized species diffusing to the substrate as well as mechanisms for ionization in the plasma. Indeed, it has recently been proposed that ion-molecule 
reactions in some plasma systems are vital for producing species that are critical to formation of particular film chemistries [10, 11, 53]. Specifically, Shamamian et al. have found that an ion-molecule protonation reaction in isopropyl alcohol plasmas leads to formation of the fragment $\mathrm{CH}_{3} \mathrm{CHCH}_{3}^{+}(\mathrm{m} / \mathrm{z}=43)$, whereas a direct electron dissociation-ionization reaction yields the $\mathrm{CH}_{3} \mathrm{CHOH}^{+}$fragment ion $(\mathrm{m} / \mathrm{z}=45)$ [11]. By controlling the plasma parameters, the $45 / 43$ ratio can be varied between 0.5 and $\sim 2.8$. As the ratio increases, the C-O character in the film increases, which is desirable for a variety of applications requiring high biocompatibility surfaces. Thus, understanding and controlling the ion-molecule reactions in a plasma can afford greater control over the resulting film chemistries. Moreover, the combination of the PI-MS, GIBMS, and IRIS data presented here clearly show that in plasma etching and deposition systems, there are strong correlations between the gas-phase ion chemistry, the plasma-surface interface reactions, and the resulting surface properties.

\section{Summary}

In both etching and deposition plasmas, ionic species play a critical role in the overall plasma process, both in the gas-phase and at the plasma-surface interface. Ion bombardment of the surface contributes to cross linking of deposited polymeric films and can also strongly influence the surface interactions of plasma radicals such as $\mathrm{SiF}_{2}$ and $\mathrm{CF}_{2}$. Under plasma etching conditions in $\mathrm{SiF}_{4}$ plasmas, large quantities of $\mathrm{SiF}_{2}$ are produced, in agreement with previous studies of F-atom etching of $\mathrm{Si}$. IRIS results for $\mathrm{CF}_{2}$ show removal of ions decreases ion-induced film sputtering, thereby lowering $\mathrm{CF}_{2}$ surface production and decreasing crosslinking in the deposited films. Our data show a clear connection between $\mathrm{CF}_{2}$ surface reactivity, ion bombardment, and film composition in $\mathrm{C}_{3} \mathrm{~F}_{8}$ and $\mathrm{C}_{4} \mathrm{~F}_{8}$ plasmas. Furthermore, comparison between our PI-MS data and the gas-phase ion-molecule work of Armentrout and coworkers demonstrate that further studies of the reactions of different diluent gases and ions may provide insight into appropriate means to manipulate the ions present in discharges under various conditions. The present results may indicate plasma conditions that could emphasize such molecular ions, which may be useful for identifying key ionized species diffusing to the substrate as well as mechanisms for ionization in the plasma.

\section{Acknowledgments}

We thank the numerous other coworkers on this project, Dr. Carmen I. Butoi, Kristen R. Kull, Dr. Galiya Malkov, Dr. Patrick R. McCurdy, Dr. Michelle L. Steen and Dr. Jianming Zhang. We also thank Dr. Jay Amicangelo and Prof. Peter Armentrout of the University of Utah for their time and effort on the GIBMS data.
Financial support for this work comes from the NSF (CHE9812332) and from the Dreyfus foundation.

\section{References}

1. Bruno, G.; Capezzuto, P.; Madan, A. Plasma deposition of amorphous silicon-based materials. Academic Press: San Diego (CA), 1995.

2. Matsumi, Y.; Toyoda, S.; Hayashi, Y.; Miyamura, M.; Yoshikawa, H.; Komiya, S. J. Appl. Phys. 1986, 60, 4102.

3. (a) Iacona, F.; Casella, G. La; Via, F.; Lombardo, S.; Raineri, V.; Spoto, G. . Microelectron. Eng. 2000, 50, 67.(b) Pankov, V.; Alonso, J. C.; Ortiz, A. Analysis of structural changes in plasma-deposited fluorinated silicon dioxide films caused by fluorine incorporation using ring-statistics based mechanism. J. Appl. Phys. 1999, 86, 275.

4. d'Agostino, R.; Cramarossa, F.; Fracassi, F.; Illuzzi, F. Plasma polymerization of fluorocarbons. Plasma deposition, treatment and etching of polymers; In: d'Agostino, R., Ed.; Academic Press: San Diego (CA), 1990; p. 95-162.

5. Mathad, G. S.; Hess, D. W.; Meyyappan, M. Plasma processing for silicon-based integrated circuits. Electrochem. Soc. Interface $1999,8,34$.

6. Hollahan, J. R.; Bell, A. T. Techniques and applications of plasma chemistry. Wiley \& Sons: New York, 1974.

7. Ada, E. T.; Kornienko, O. Hanley, L. Chemical modification of polystyrene surfaces by low-energy polyatomic ion beams. J. Phys. Chem. B. 1998, 102, 3959.

8. Wijesundara, M. B. J.; Ji, Y.; Ni, B.; Sinnott, S. B.; Hanley, L. Effect of polyatomic ion structure on thin-film growth: Experiments and molecular dynamics simulations. J. Appl. Phys. 2000, 88, 5004 .

9. Wijesundara, M. B. J.; Hanley, L.; Ni, B.; Sinnott, S. B. Effects of unique ion chemistry on thin-film growth by plasmasurface interactions. Proc. Natl. Acad. Sci. 2000, 97, 23.

10. Beck, A. J.; Candan, S.; Short, R. D.; Goodyear, A. ; Braithwaite, $\mathrm{N}$. St. J. The role of ions in the polasma polymerization of Allylamine. J. Phys. Chem. B. 2001, 105, 5730 [and references therein].

11. Shamamian, V. A.; Hinshelwood, D. D.; Guerin, D. C.; Denes, F. S.; Manolache, S. Mass spectrometric characterization of pulsed inductively coupled plasmas for deposition of thin polyethylene glycol-like polymer films. J. Photopolym. Sci. Technol. 2001, 14, 91.

12. Stoffels, W. W.; Stoffels, E.; Tachibana, K. Polymerization of fluorocarbons in reactive ion etching plasmas. J. Vac. Sci. Technol. A. 1998, 16, 87.

13. Armentrout, P. B. Kinetic energy dependence of ion-molecule reactions related to plasma chemistry. In: Inokuti, M.; Becker, K., Eds. Fundamentals of plasma chemistry, 43. Academic: New York, 2000; 187-229 [Adv. Atomic, Molec., and Optical Phys.].

14. (a) Sugai, H.; Mitsuoka, Y.; Toyoda, H. Observation of surface dissociation of low-energy polyatomic ions relevant to plasma processing. J. Vac. Sci. Technol. A. 1998, 16, 290. (b) Mitsuoka, Y.; Toyoda, H.; Sugai, H. Dissociative ion yields on metalsurfaces bombarded with low-energy fluorocarbon ions. Jpn. J. Appl. Phys. 1995, 34, L1486.

15. (a) Abrams, C. F.; Graves, D. B. On the active surface layer in $\mathrm{CF}_{3}^{+}$etching of Si: Atomistic simulation and a simple mass balance model. J. Vac. Sci. Technol. A. 2000, 18, 411. (b) Abrams, C. F.; Graves, D. B. Atomistic simulation of silicon bombardment by energetic $\mathrm{CF}_{3}^{+}$: Product distributions and energies. Thin Solid Films 2000, 374, 150.

16. Abrams, C. F.; Graves, D. B. Atomistic simulation of fluorocarbon deposition on Si by continuous bombardment with energetic $\mathrm{CF}^{+}$and $\mathrm{CF}_{2}^{+}$. J. Vac. Sci. Technol. A. 2001, 19, 175. 
17. McCurdy, P. R.; Bogart, K. H. A.; Dalleska, N. F.; Fisher, E. R. A modified molecular beam instrument for the imaging of radicals interacting with surfaces during plasma processing. Rev. Sci. Instrum. 1997, 68, 1684.

18. McCurdy, P. R.; Venturo, V. A.; Fisher, E. R. Velocity distributions of $\mathrm{NH}_{2}$ radicals in an $\mathrm{NH}_{3}$ plasma molecular beam. Chem. Phys. Lett. 1997, 274, 120.

19. McCurdy, P. R.; Butoi, C. I.; Williams, K. L.; Fisher, E. R. Surface interactions of $\mathrm{NH}_{2}$ radicals in $\mathrm{NH}_{3}$ plasmas. J. Phys. Chem. B. 1999, 103, 6919.

20. Butoi, C. I.; Steen, M. L.; Peers, J. R. D.; Fisher, E. R. Mechanisms and energy transfer for surface generation of $\mathrm{NH} 2$ radicals during $\mathrm{NH}_{3}$ plasma processing of metal and polymer substrates. J. Phys. Chem. B. 2001, 105, 2749.

21. Bogart, K. H. A.; Cushing, J. P.; Fisher, E. R. Effects of plasma processing parameters on the surface reactivity of $\mathrm{OH}\left(\mathrm{X}^{2} \Pi\right)$ in tetraethoxysilane $/ \mathrm{O}_{2}$ plasmas during deposition of $\mathrm{SiO}_{2}$. J. Phys. Chem. B. 1997, 101, 10016.

22. (a) Mackie, N. M.; Dalleska, N. F.; Castner, D. G.; Fisher, E. R. Comparison of pulsed and continuous wave deposition of thin films from fluorocarbon $/ \mathrm{H}_{2}$ inductively coupled $\mathrm{rf}$ plasmas. Chem. Mater. 1997, 9, 349. (b) Martin, I. T.; Malkov, G.; Fisher, E. R. unpublished work.

23. Ervin, K. M.; Armentrout, P. B. Translational energy dependence of $\mathrm{Ar}++\mathrm{XY} \rightarrow \mathrm{ArX}++\mathrm{Y}\left(\mathrm{XY}=\mathrm{H}_{2}, \mathrm{D}_{2}\right.$, HD) from thermal to $30 \mathrm{eV} \mathrm{cm}$. J. Chem. Phys. 1985, 83, 166.

24. Teloy, E.; Gerlich, D. Integral cross-sections for ion-molecule reactions. 1. Guided beam technique. Chem. Phys. 1974, 4, 417.

25. (a) Okada, Y.; Wagner, S. Etching of crystalline silicon using germanium tetrafluoride. J. Electrochem. Soc. 1990, 1957. (b) Darcy, A.; Galijatovic, A.; Barth, R.; Kenny, T.; Krantzman, K. D.; Schoolcraft, T. A. Molecular dynamics simulations of silicon-fluorine etching. J. Mol. Graphics 1996, 14, 260. (c) van den Hoek, P. J.; Ravenek, W.; Baerends, E. J. Phys. Rev. B. 1988, 38, 12508. (d) Sparks, D. R. J. Electrochem. Soc. 1992, 139, 1736. (e) Boyd, H.; Tang, M. J. Applications for silicon tetrafluoride in plasma-etching. Solid State Technol. 1979, 22, 133. (f) Hayashi, H.; Kurihara, K.; Sekine, M. Characterization of highly selective $\mathrm{SiO}_{2} / \mathrm{Si}_{3} \mathrm{~N}_{4}$ etching of high-aspect-ratio holes. Jpn. J. Appl. Phys. 1996, 35, 2488.

26. Winters, H. F.; Coburn, J. W. Surface science aspects of etching reactions. Surf. Sci. Rep. 1992, 14, 161.

27. Uchida, Y.; Taguchi, K.; Sugahara, S.; Matsumura, M. A fluorinated organic-silica film with extremely low dielectric constant. Jpn. J. Appl. Phys. 1999, 38(1), 2368.

28. (a) Lee, H.; Deneufville, J. P. LIF and OES detection of radical species in $\mathrm{SiF}_{4}$ and $\mathrm{H}_{2}$ plasmas. J. Non-Cryst. Solid 1984, 39, 66. (b) Lee, H.; Deneufville, J. P.; Ovshinsky, S. R. Laser-induced fluorescence detection of reactive intermediates in diffusion flames and in glow-discharge deposition reactors. J. NonCryst. Solid 1983, 59-60, 671.

29. Cicala, G.; Bruno, G.; Capezzuto, P. Plasma deposition of amorphous silicon alloys from fluorinated gases. Pure Appl. Chem. 1996, 68, 1143.

30. Williams K. L.; Fisher E. R.J. Vac. Sci. Technol. A. (manuscript in preparation)

31. Steen M. L.; Kull K. R.; Fisher E. R. Comparison of surface interactions for $\mathrm{NH}$ and $\mathrm{NH} 2$ radicals on polymer and metal substrates. J. Appl. Phys., in press.

32. Weber, M. E.; Armentrout, P. B. Reactions of $\mathrm{Ar}+, \mathrm{Ne}+$, and $\mathrm{He}+$ with $\mathrm{SiF}_{4}$ from thermal energy to $50 \mathrm{eV} \mathrm{cm}$. J. Chem. Phys. 1989, 90, 2213.

33. Weber, M. E.; Armentrout, P. B. Energetics and dynamics in the reaction of $\mathrm{Si}^{+}$with $\mathrm{SiF}_{4}$. Thermochemistry of $\mathrm{SiF}_{\mathrm{x}}$ and $\mathrm{SiF}_{\mathrm{x}}^{+}(\mathrm{x}=1,2,3) . J$. Chem. Phys. 1988, 88, 6898.

34. Kickel, B. L.; Fisher, E. R.; Armentrout, P. B. Dissociative charge transfer reactions of $\mathrm{N}^{+}, \mathrm{N}_{2}^{+}$and $\mathrm{Ar}^{+}\left({ }^{2} \mathrm{P}_{3 / 2}\right)$ with $\mathrm{SiF}_{4}$.
Thermochemistry of $\mathrm{SiF}_{4}^{+}$and $\mathrm{SiF}_{3}^{+}$. J. Phys. Chem. 1993, 97, 10198.

35. Fisher, E. R.; Armentrout, P. B. Translational and internal energy effects in reactions of $\mathrm{O}^{+}$and $\mathrm{O}_{2}^{+}$with $\mathrm{SiF}_{4}$. Chem. Phys. Lett. 1991, 179, 435.

36. Zhang J.; Fisher E. R. unpublished work.

37. Senzer, S. N.; Lampe, F. W. Gaseous ion reactions in $\mathrm{SiF}_{4}$ and $\mathrm{SiF}_{4}-\mathrm{D}_{2}$ mixtures. J. Appl. Phys. 1983, 54, 3524.

38. Lieberman, M. A.; Lichtenberg, A. J. Principles of plasma discharges and material processing. Wiley \& Sons: New York, 1994.

39. Butoi, C. I.; Mackie, N. M.; Williams, K. L.; Capps, N. E.; Fisher, E. R. Ion and substrate effects on surface reactions of $\mathrm{CF}_{2}$ using $\mathrm{C}_{2} \mathrm{~F}_{6}, \mathrm{C}_{2} \mathrm{~F}_{6} / \mathrm{H}_{2}$ and hexafluoropropylene oxide plasmas. J. Vac. Sci. Technol. A. 2000, 18, 2685.

40. Abrams, C. F.; Graves, D. B. Molecular dynamics simulations of Si etching by energetic $\mathrm{CF}_{3}^{+}$. J. Appl. Phys. 1999, 86, 5938.

41. Murri, R.; Schiavulli, L.; Bruno, G.; Capezzuto, P.; Grill, G. Deposition rate, ion-bombardment and gap states density in glow-discharge a-Si-H,F films. Thin Solid Films 1989, 182, 105.

42. Miyata, K.; Hori, M.; Goto, T. CFX $(X=1-3)$ radical densities during $\mathrm{Si}, \mathrm{SiO}_{2}$, and $\mathrm{Si}_{3} \mathrm{~N}_{4}$ etching employing electron cyclotron resonance $\mathrm{CHF}_{3}$ Plasma. J. Vac. Sci. Technol. A. 1997, 15, 568.

43. Tserepi, A. D.; Derouard, J.; Booth, J. P.; Sadeghi, N. $\mathrm{CF}_{2}$ kinetics and related mechanisms in the presence of polymers in fluorocarbon plasmas. J. Appl. Phys. 1997, 81, 2124.

44. Williams K. L.; Zhang J.; Fisher E. R. unpublished work.

45. Mackie, N. M.; Capps, N. E.; Butoi, C. I.; Fisher, E. R. Radical surface reactivities of $\mathrm{CF}_{2}$ during deposition of amorphous fluorocarbon films. ACS Symp. Ser. 2001, 787, 168 [Fluorinated Coatings, Surfaces, and Films].

46. Butoi, C. I.; Mackie, N. M.; Gamble, L. J.; Castner, D. G.; Miller, A. M.; Barnd, J. E.; Fisher, E. R. Deposition of highly ordered $\mathrm{CF}_{2}$-rich films using $\mathrm{CW}$ and pulsed hexafluoropropylene oxide plasmas. Chem. Mater. 2000, 12, 2014.

47. Mackie, N. M.; Castner, D. G.; Fisher, E. R. Characterization of pulsed plasma polymerized aromatic films. Langmuir 1998, 14, 1227.

48. Vartanian, V.; Beu, L.; Lii, T.; Graves, D.; Tonnis, E. J.; Jewett, R.; Wofford, B.; Beva, J.; Hartz, C.; Gunn, M. Plasma abatement reduces PFC emission. Semicon. Intern. 2000, 23, 191.

49. (a) Cunge, G.; Booth, J. P. $\mathrm{CF}_{2}$ production and loss mechanisms in fluorocarbon discharges: Fluorine-poor conditions and polymerization. J. Appl. Phys. 1999, 85, 3952. (b) Schwarzenbach, W.; Cunge, G.; Booth, J. P. High mass positive ions and molecules in capacitively-coupled radio-frequency $\mathrm{CF}_{4}$ plasmas. J. Appl. Phys 1999, 85, 7562. (c) Haverlag, M.; Stoffels, W. W.; Stoffels, E.; Kroesen, G. M. W.; de Hoog, F. J. Production and destruction of $\mathrm{CF}_{\mathrm{x}}$ radicals in radio-frequency fluorocarbon plasmas. J. Vac. Sci. Technol. A. 1996, 14, 384. (d) Haverlag, M.; Stoffels, W. W.; Stoffels, E.; Kroesen, G. M. W.; de Hoog, F. J. Measurements of radical densities in radiofrequency fluorocarbon plasmas using infrared absorption spectroscopy. J. Vac. Sci. Technol. A. 1994, 12, 3102.

50. Rinsch, C. L.; Chen, X.; Panchalingam, V.; Eberhart, R. C.; Wang, J. H.; Timmons, R. B. Pulsed radio frequency plasma polymerization of allyl alcohol: Controlled deposition of surface hydroxyl Groups. Langmuir 1996, 12, 2995.

51. Capps, N. E.; Mackie, N. M.; Fisher, E. R. Surface interactions of $\mathrm{CF}_{2}$ radicals during deposition of amorphous fluorocarbon films from $\mathrm{CHF}_{3}$ plasmas. J. Appl. Phys. 1998, 84, 4736.

52. Martin I. T.; Fisher E. R.; Amicangelo J. A.; Armentrout P. B. J. Phys. Chem. (manuscript in preparation).

53. Barton, D.; Bradley, J. W.; Gibson, K. J.; Steele, D. A.; Short, R. D. An in-situ comparison between vuv photon and ion energy fluxes to polymer surfaces immersed in an rf plasma. J. Phys. Chem. B. 2000, 104, 7150. 